\title{
VEGF $_{189}$ Expression Is Highly Related to Adaptation of the Plateau Pika (Ochotona curzoniae) Inhabiting High Altitudes
}

\author{
Hongge Li, ${ }^{1,2, \star}$ Songchang Guo, ${ }^{1}$ Yongming Ren, ${ }^{3}$ Depeng Wang, ${ }^{1,2}$ Honghao $\mathrm{Yu},{ }^{1,2}$ \\ Wenjing $\mathrm{Li}^{1,}{ }^{1,2}$ Xinquan Zhao, ${ }^{1}$ and Zhijie Chang ${ }^{3}$
}

\begin{abstract}
Li, Hongge, Songchang Guo, Yongming Ren, Depeng Wang, Honghao Yu, Wenjing Li, Xinquan Zhao, and Zhijie Chang. VEGF 189 expression is highly related to adaptation of the plateau pika (Ochotona curzoniae) inhabiting high altitudes. High Alt Med Biol 14:395-404, 2013.- The plateau pika (Ochotona curzonia) has adapted to high-altitude hypoxia during evolution. Higher microvessel density in specific tissues and a blunted hypoxic pulmonary vasoconstriction response are the critical components of this adaptation. VEGF, vascular endothelial growth factor, has proved to be a key regulator of angiogenesis in response to tissue hypoxia and to play an important role in vascular vasodilation. However, the role of VEGF in adaptation to high-altitude hypoxia in the plateau pika remains unknown. In this study, we cloned cDNAs for VEGF 165 and VEGF $_{189}$ and examined their expression in pikas inhabiting altitudes of 3200 and $4750 \mathrm{~m}$. Phylogenetic analysis reveals that pika VEGF 165 and VEGF $_{189}$ are evolutionarily conserved. Real-time PCR analysis demonstrates that VEGF 165 and $\mathrm{VEGF}_{189}$ display tissue and altitude-specific expression patterns. Interestingly, we found that the levels of VEGF $_{189}$ mRNA are significantly higher than those of VEGF $_{165}$ in the brain and muscle tissues of the pika,

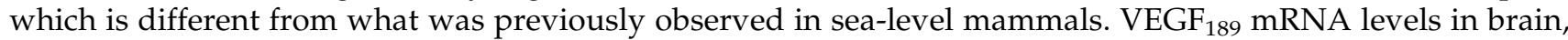
muscle, and lung of the pika increased with increased habitat altitude, whereas VEGF 165 shows less change. Our study suggests an important role for $\mathrm{VEGF}_{189}$ in adaptation to hypoxia by the plateau pika in the highaltitude environment.
\end{abstract}

Key Words: adaptation; Qinghai-Tibetan plateau; hypoxia; plateau pika; VEGF; real-time PCR

\section{Introduction}

$\mathbf{H}$ YPOXIA AND COLD CLIMATE are the two most important ecological challenges for plateau animals. Native highaltitude animals have developed unique cardiovascular, hematological, and respiratory systems that ensure a successful adaptation to the harsh environment. Higher microvessel density, increased red blood corpuscle count, and blunted hypoxic pulmonary vasoconstriction response, which help animals to adapt to high-altitude hypoxia, have been reported in many plateau mammals (Anand et al., 1988, Anand et al.,
1986, Azwai et al., 2007, Benavides et al., 1989, Durmowicz et al., 1993, Ge et al., 1998, Jiang et al., 1991, Jiang et al., 1992, Qi et al., 2008, Wang et al., 2008, Wei et al., 2006, Ye et al., 1994).

The plateau pika (Ochotona cuzoniae) is a small, nonhibernating mammal that inhabits alpine meadows above $3000 \mathrm{~m}$, and is a keystone species on the Qinghai-Tibetan plateau ecosystem (Fig. 1). Over the course of evolution, the plateau pika has acquired a remarkable tolerance to hypoxia and the cold plateau environment by improving the utilization of oxygen (Du et al., 1982), increasing the resting

\footnotetext{
${ }^{1}$ Key Laboratory of Adaptation and Evolution of Plateau Biota, Northwest Institute of Plateau Biology, The Chinese Academy of Sciences, Xining, China.

${ }^{2}$ Graduate University of Chinese Academy of Sciences, Beijing, China.

${ }^{3}$ School of Medicine, Department of Biological Sciences and Biotechnology, State Key Laboratory of Biomembrane and Membrane Biotechnology, Tsinghua University, Beijing, China.

*Present address: Department of Medical and Molecular Genetics, Indiana University School of Medicine, Indianapolis, IN 46202, USA.
} 

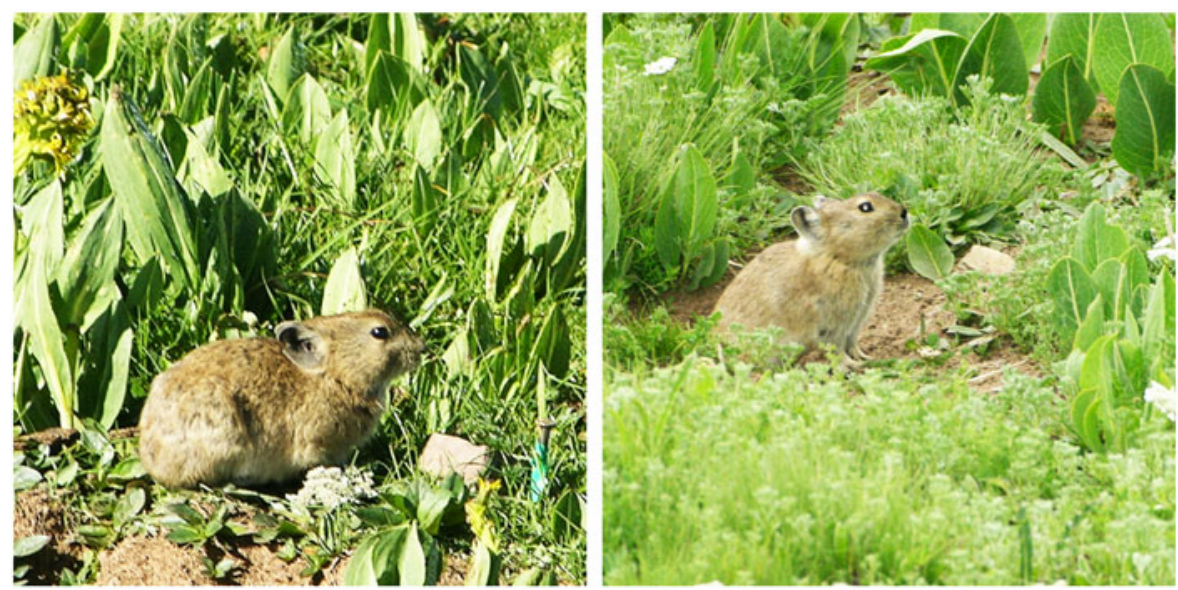

FIG. 1. The plateau pika (Ochotona curzoniae), also known as the black-lipped pika, is a species of mammal in the Ochotonidae family commonly known as pika. They prefer to live in elevation of 3000 to $5000 \mathrm{~m}$, mostly in the Tibetan Plateau.

metabolic rate, and having a nonshivering thermogenesis $(\mathrm{Li}$ et al., 2001). A number of strategies that are used by the pika to adapt to the harsh environment have been elucidated. These strategies include: 1) an increase in erythrocyte count, reduction in the mean corpuscular volume (Ye et al., 1994), changes in hemoglobin $(\mathrm{Hb})$ and 2,3-diphosphoglycerate concentrations (Ge et al., 1998), and an increase in the oxygen affinity to $\mathrm{Hb}$ (He et al., 1994); 2) adaptation to its environment in terms of hepatic function, metabolism (Li et al., 1986), and neuroendocrine function (Du et al., 1983, Wu et al., 2001); 3) blunted hypoxic pulmonary vasoconstriction and thinwalled pulmonary arterioles (Ge et al., 1998); and 4) higher capillary densities, mitochondrial density, and concentration of myoglobin (for heart) in heart and lung (Qi et al., 2008, Wang et al., 2008). All these strategies reveal that the pika's adaptation to high altitudes occurs at both the physiological and biochemical levels.

The molecular basis of these adaptations in the pika have occurred because of evolutionary changes in several critical factors, including HIF- $1 \alpha$ (Li et al., 2008, Zhao et al., 2004), leptin (Yang et al., 2006, 2008), and hemoglobin (Yingzhong et al., 2007). These factors have been reported to be expressed in a tissue-specific manner (Zhao et al., 2004) and with changes that are related to altitude (Li et al., 2008, Yang et al., 2006).

Vascular endothelial growth factor (VEGF) plays a key role in angiogenesis, the formation of new capillaries from preexisting vasculature, during development and in response to tissue hypoxia. In addition, VEGF has been reported to cause vasodilatation in vitro in a dose-dependent manner ( $\mathrm{Ku}$ et al., 1993) and to have effects on hematopoiesis and bone marrowderived cells (Broxmeyer et al., 1995, Gerber et al., 2002, Hattori et al., 2001). Furthermore, VEGF expression is tightly regulated at the levels of transcription, mRNA stability (Levy et al., 1998) and translation (Stein et al., 1998) under hypoxia. Hypoxia inducible factor 1 (HIF-1), a key mediator of the hypoxic response, induces transcription of VEGF (Forsythe et al., 1996).

VEGF is expressed as several different isoforms due to alternative splicing of the primary transcript depending on the presence or absence of exons 6 and 7 (Yamazaki et al., 2006). These isoforms have differing affinity for heparin, therefore are either secreted (soluble, $\mathrm{VEGF}_{121}$ and $\mathrm{VEGF}_{165}$ ) or cell- or matrix-associated $\left(\mathrm{VEGF}_{189}, \mathrm{VEGF}_{206}\right.$, and partially $\left.\mathrm{VEGF}_{165}\right)$. The different isoforms also have differing binding affinity to the VEGF receptors (Gitay-Goren et al., 1992), which results in the diversity of their bioactivities (Yamazaki et al., 2006).

Since VEGF has a fundamental role in angiogenesis, the response to hypoxia and its effects on vasodilation, we hypothesize that VEGF may have a different expression pattern in the plateau pika. In this study, we cloned cDNAs for the VEGF $_{165}$ and VEGF $_{189}$ isoforms from pika, and determined their expression patterns in the plateau pika. Our results show that $\mathrm{VEGF}_{165}$ and $\mathrm{VEGF}_{189}$ display tissue and altitude-specific expression patterns in this animal.

\section{Materials and Methods}

\section{Animal tissue preparation}

Plateau pikas were captured near the Haibei Alpine Meadow Research Station, Chinese Academy of Sciences (altitude $3200 \mathrm{~m}$ ) and Hoh Xil region near Kunlun Mountain (altitude $4750 \mathrm{~m}$ ) where vegetation type is alpine meadow in Qinghai province, China. The annual mean air temperatures at these two sites are $-1.7^{\circ} \mathrm{C}$ and $-11.7^{\circ} \mathrm{C}$, respectively, for the last decade. Zhou Le et al. found that genetic distance and geographical distance of plateau pika population have no significant correlation (Zhou et al., 2007). Yang et al. (2008) found that altitude has no significant effect on substitution rates of the gene-like leptin in pika. Here ten individuals of plateau pika from each site were used for mRNA analysis. Animals were killed by cervical dislocation and immediately dissected at collection. Heart, lung, liver, spleen, kidney, brain, and muscle tissues were rapidly removed and frozen in liquid nitrogen. All procedures involving the handling and care of animals were in accordance with China's Practice for the Care and Use of Laboratory Animals and were approved by the Chinese Zoological Society.

\section{RNA and cDNA preparation}

Total RNA was extracted and purified from heart, lung, liver, spleen, kidney, brain, and muscle tissues of the plateau pika using TRIZOL reagent (Invitrogen, Carlsbad, CA, USA). RNA samples were then treated with RNase-free DNase I (TaKaRa Biotechnology Co. Ltd., Dalian, China), and the 
concentration was determined with an Ultrospec 3000 . RNA integrity was tested by electrophoresis through a formaldehyde-denaturing $1 \%$ agarose gel. Four micrograms of total RNA treated with DNase I were used for first-strand cDNA synthesis using the RevertAid ${ }^{\mathrm{TM}} \mathrm{H}$ Minus First Strand cDNA Synthesis kit (MBI, Fermantase, Opelstr., Germany) with oligo $(\mathrm{dT})_{18}$ primers in a final volume of $20 \mu \mathrm{L}$. Once synthesized, cDNA samples were diluted 20-fold with nuclease-free water and used for standard PCR or real-time PCR reactions.

\section{Cloning}

Primers were designed based on the full-length coding sequence (CDS) of human, mouse, and Norway rat $\mathrm{VEGF}_{165}$ / 164. Primers are shown in Figure 2. Using plateau pika brain and muscle cDNA as templates, amplification was carried out with an initial denaturation at $94^{\circ} \mathrm{C}$ for $5 \mathrm{~min}$, followed by 30 cycles of $94^{\circ} \mathrm{C}$ for $40 \mathrm{sec}, 52^{\circ} \mathrm{C}$ for $30 \mathrm{sec}$ and $72^{\circ} \mathrm{C}$ for $1 \mathrm{~min}$, and a final extension at $72^{\circ} \mathrm{C}$ for $10 \mathrm{~min}$. Amplified DNA fragments were subcloned into the pGEM-T Easy Vector (Promega, Madison, WI, USA) and sequenced.

\section{Sequence analysis}

The CDS of plateau pika VEGF was translated to obtain the protein sequence using BioEdit software. Multiple sequence alignments were performed with the deduced $\mathrm{VEGF}_{165 / 164}$ and $\mathrm{VEGF}_{189 / 188}$ protein sequences of Ochotona curzoniae, Homo sapiens ( VEGF $_{165}$, AAA35789; VEGF ${ }_{189}, \mathrm{CAC19513}$, Oryctolagus cuniculus (Watkins et al., 1999), Rattus norvegicus (VEGF $_{164}$, AAL07526; VEGF 188 , AAL07528), and Mus musculus (VEGF $164, \mathrm{NP}_{2} 033531 ; \mathrm{VEGF}_{188}, \mathrm{NP}_{2}$ 001020421) using CLUSTAL X 1.81 (Thompson et al., 1994). Phylogenetic trees were constructed from the amino acid sequences of VEGF V65 $_{\text {/ }}$ 164 and $\mathrm{VEGF}_{189 / 188}$ of plateau pika and other species using the neighbor-joining method with MEGA version 4.0 (Tamura et al., 2007).

\section{$R T-P C R$ analysis}

Expression of total VEGF, VEGF 165 , and VEGF $_{189}$ mRNAs were determined in pika heart, lung, liver, spleen, kidney, brain, and muscle by a one-step RT-PCR method. Aliquots of total RNA were reverse-transcribed at $50^{\circ} \mathrm{C}$ for $30 \mathrm{~min}$. The primers (sense, 5'TTGCTGCTCTACCTCCAC3'; antisense, 5'ATGTCCACCAAGGTCTCG3') for the amplification of total VEGF were designed in the common coding regions (nucleotides 1-422) of all VEGF isoforms. One pair of primers was designed to determine both $\mathrm{VEGF}_{165}$ and $\mathrm{VEGF}_{189}$. PCR products from this pair of primers have different sizes and can be separated on gel electrophoresis. These primers are shown in Figure1.

\section{Real-time PCR analysis}

PCR amplification was performed by using SYBR Green$\mathrm{ER}^{\mathrm{TM}} \mathrm{qPCR}$ Supermix (Invitrogen) in a final reaction volume of $20 \mu \mathrm{L}$. Each reaction contained $0.8 \mu \mathrm{L}$ of diluted cDNA samples or plasmid along with $200 \mathrm{nM}$ primers. For standard curves, dilutions of plasmid-DNA constructs containing the amplicons of each gene were used. The PCR plate was incubated at $50^{\circ} \mathrm{C}$ for $2 \mathrm{~min}$ and $95^{\circ} \mathrm{C}$ for $10 \mathrm{~min}$, followed by 40 cycles of $95^{\circ} \mathrm{C}$ for $15 \mathrm{sec}$ and $60^{\circ} \mathrm{C}$ for $1 \mathrm{~min}$. Absolute gene quantification was carried out using the ABI PRISM 7000 Sequence Detection System (Applied Biosystems, Foster City, CA, USA). Samples were isolated from individual animals, and each sample was tested in triplicate. Normalization was done by dividing the average expression measurement of each gene by that of $\beta$-actin in each sample.

In order to specifically amplify pika $\mathrm{VEGF}_{165}$ or $\mathrm{VEGF}_{189}$, reverse primers specific to each sequence were designed,

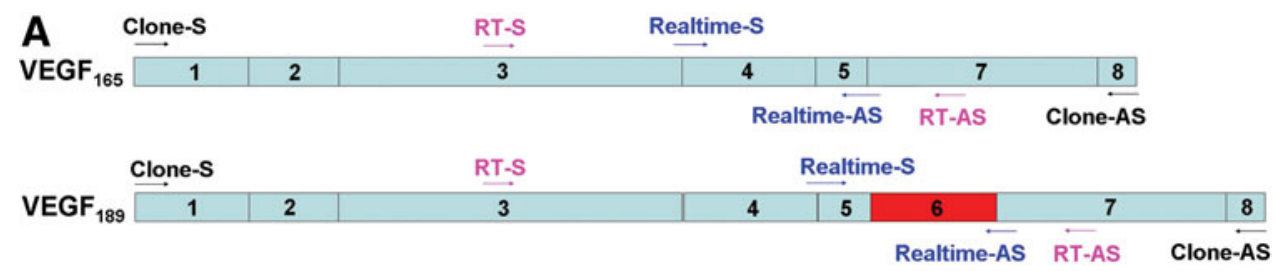

B

\begin{tabular}{|c|c|c|}
\hline Primer name & Sequence & Exon junc. \\
\hline VEGF $_{165 / 189-C l o n e-S}$ & 5'-ATG AAC TTT CTG CT(C/G) TCT Tg -3' & 1 \\
\hline VEGF $_{165 / 189-C l o n e-A S}$ & 5'-TCA CCG CCT TGG CTT GTC -3 , & 8 \\
\hline VEGF $_{165 / 189-R T-S}$ & 5'-TCT TCA AGC CAT CCT GTG -3 ', & 3 \\
\hline VEGF $_{165 / 189}$-RT-AS & 5'-AAA TGC TTT CTC CGC TCT -3 ', & 7 \\
\hline VEGF $_{165}$-Realtime-S & 5'-GCA GAT CAT GCG GAT CAA AC -3, & $3-4$ \\
\hline VEGF $_{165}$-Realtime-AS & 5'-CCA CAG GGA TTT TCT TGT CTT G -3' & $5-7$ \\
\hline VEGF $_{189}$-Realtime-S & $5^{\circ}$-ATG CAG ACC AAA GAA AGA TAG AG $-3^{\circ}$ & $4-5$ \\
\hline VEGF $_{189}$-Realtime-AS & 5'-GCA AGG CCC ACA GGG AGC -3' & $6-7$ \\
\hline Actin-S & 5'-AGG TCA TCA CCA TCG GCA AC -3' & \\
\hline Actin-AS & 5'-TGG AGT TGA AGG TCG TCT CGT -3, & \\
\hline
\end{tabular}

FIG. 2. PCR primers used for RT-PCR and real-time RT-PCR. (A) Schematic of the plateau pika VEGF 165 and VEGF 189 open reading frames (ORFs). Exons are indicated with 1, 2, 3, 4, 5, 6, 7, and 8. The black, pink, and blue arrows indicate the positions of the PCR primers for cloning, RT-PCR, and real-time RT-PCR analysis, respectively. The red part is exon 6 of the pika VEGF $_{189}$, which is not found in pika VEGF 165 . (B) Primers used in the clone, RT-PCR, and real-time RT-PCR analysis. 
which also do not allow genomic DNA to be amplified. All primers are shown in Figure 2.

\section{Data analysis}

Statistical analyses were performed using SPSS 13.0 software. A student's $t$-test was used to evaluate the significance of differences between groups of experiments. All values were expressed as mean \pm S.D. and $\mathrm{P}<0.05$ was considered to be statistically significant.

\section{Results}

\section{Cloning and characterization of VEGF cDNAs in the plateau pika}

We cloned two VEGF isoforms from the brain and muscle of plateau pika with full-length CDS of $576 \mathrm{bp}$ and $648 \mathrm{bp}$. These two isoforms of pika VEGF were predicted to contain 191 and 215 amino acids, both with an apparent signal peptide (26 amino acids). The nucleotide sequences and the predicted amino acid sequences are presented in Figure 3 and were deposited in GenBank (cDNA: EU262733 and EU262734; protein: ACA23169 and ACA23170, respectively). The mature secreted proteins are predicted to be 165 and 189 amino acids in length; therefore we named the two isoforms $\mathrm{pVEGF}_{165}$ and $\mathrm{pVEGF}_{189}$, respectively. The molecular weights (MW) of the two isoforms were calculated to be $19.43 \mathrm{KDa}$ and $22.32 \mathrm{KDa}$ and have isoelectric points $(\mathrm{p} I)$ of 7.93 and 9.27. The pika VEGFs were predicted to have one $\mathrm{N}$-glycosylation site, one $\mathrm{N}$-myristoylation site, one casein kinase II phosphorylation site, five protein kinase $\mathrm{C}$ phosphorylation sites, and one cAMP- and cGMPdependent protein kinase phosphorylation site. In addition, there is one bipartite nuclear localization signal profile in $\mathrm{VEGF}_{189}$.

Analysis of the amino acid sequence reveals that the pika VEGF $_{165}$ shares $94,96,90,90,95,96,75$, and $76 \%$ of identity to orthologs in human, rabbit, mouse, Norway rat, bovine, dog, chicken, and African clawed frog. The amino acid sequence identity of pika $\mathrm{VEGF}_{189}$ to orthologs in human, rabbit, mouse, Norway rat, dog, and chicken is also high $(94,96,90,90,95$, and $76 \%$, respectively). Cysteine residues, which can form disulfide bonds, at positions 26, 51, 57, 60, 61, 68, 102, and 104 of the receptor-binding domain; and 141, 144, 159, 161, 163, 170, 182, and 184 in the heparin-binding domain of pika VEGF $_{165}$ and VEGF $_{189}$ are highly conserved among species (Fig. 4).

Phylogenetic trees were constructed based on the VEGF 165 and $\mathrm{VEGF}_{189}$ sequences of plateau pika and the other vertebrates, respectively. The results indicate that both $\mathrm{VEGF}_{165}$ and $\mathrm{VEGF}_{189}$ from pika are most closely related to those from the rabbit (Fig. 5A and B). These phylogenetic trees are in accordance with those obtained from hemoglobin (Yingzhong et al., 2007), HIF- $1 \alpha$, and Cytb (not published).

Pika and human VEGF 165 and VEGF 189 show some differences, although they are highly conserved. Differences occur in the receptor-binding domain for both $\mathrm{VEGF}_{165}$ and VEGF $_{189}$ (Glu6Gly, Asp8Gly, His9Gln, Lys10Asn, Pro11His, Arg22Gln, Arg27His, Ala58Gly, Ser65Gly, and Phe74Ser in mature protein) as well as a change in Ala139Val, next to the heparin-binding domain of $\mathrm{VEGF}_{189}$ (Fig. 6).

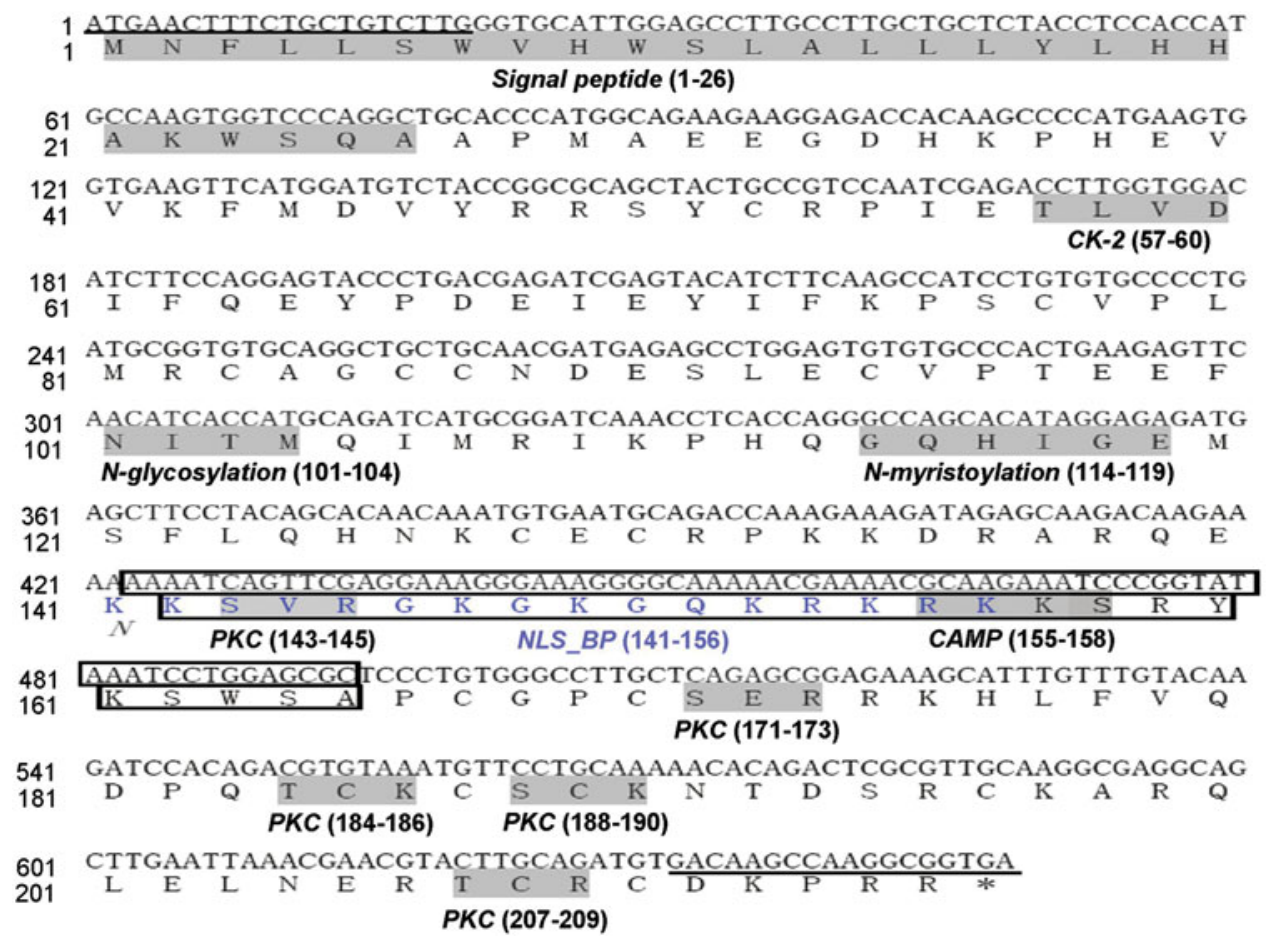

FIG. 3. Plateau pika VEGF cDNA and deduced amino acid sequence. The sequence represents the combined sequence of two cDNA derived from pika VEGF 165 and $\mathrm{VEGF}_{189}$. Predicted motifs and the signal peptide sequence are shaded with a gray background with abbreviated names under them. The blue font indicates a bipartite nuclear localization signal profile (NLS_BP) in VEGF $_{189}$. The part of the cDNA $(72 \mathrm{bp})$ and amino acid sequence (24aa) missing in VEGF 165 is boxed. Oligonucleotide primers used to generate the clones are underlined. The abbreviation for the motifs are: CK-2, casein kinase II phosphorylation site; N-glycosylation, N-glycosylation site; N-myristoylation, N-myristoylation site; PKC, protein kinase C phosphorylation site; CAMP, cAMP- and cGMP-dependent protein kinase phosphorylation site. 


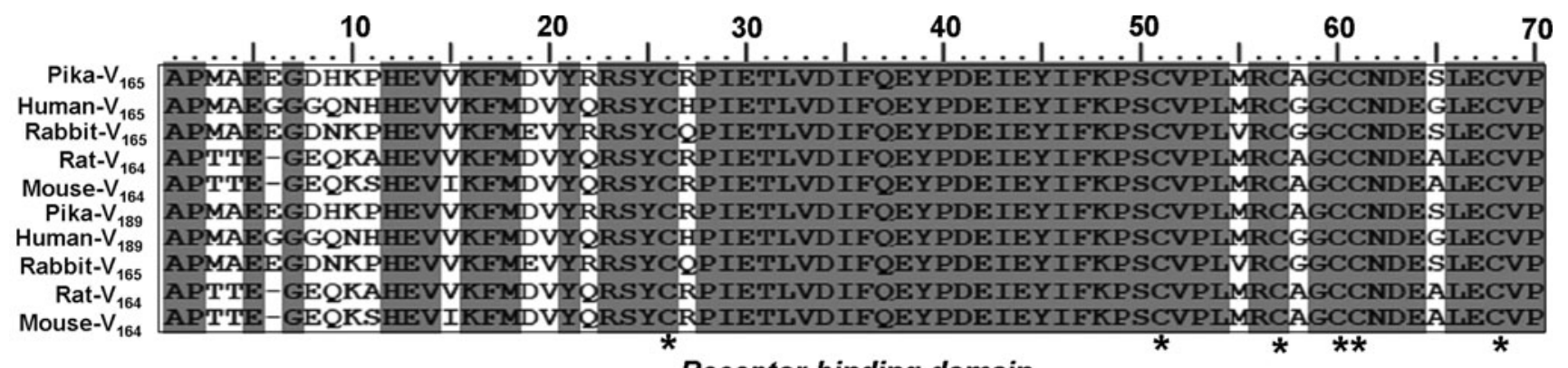

\section{Receptor-binding domain}
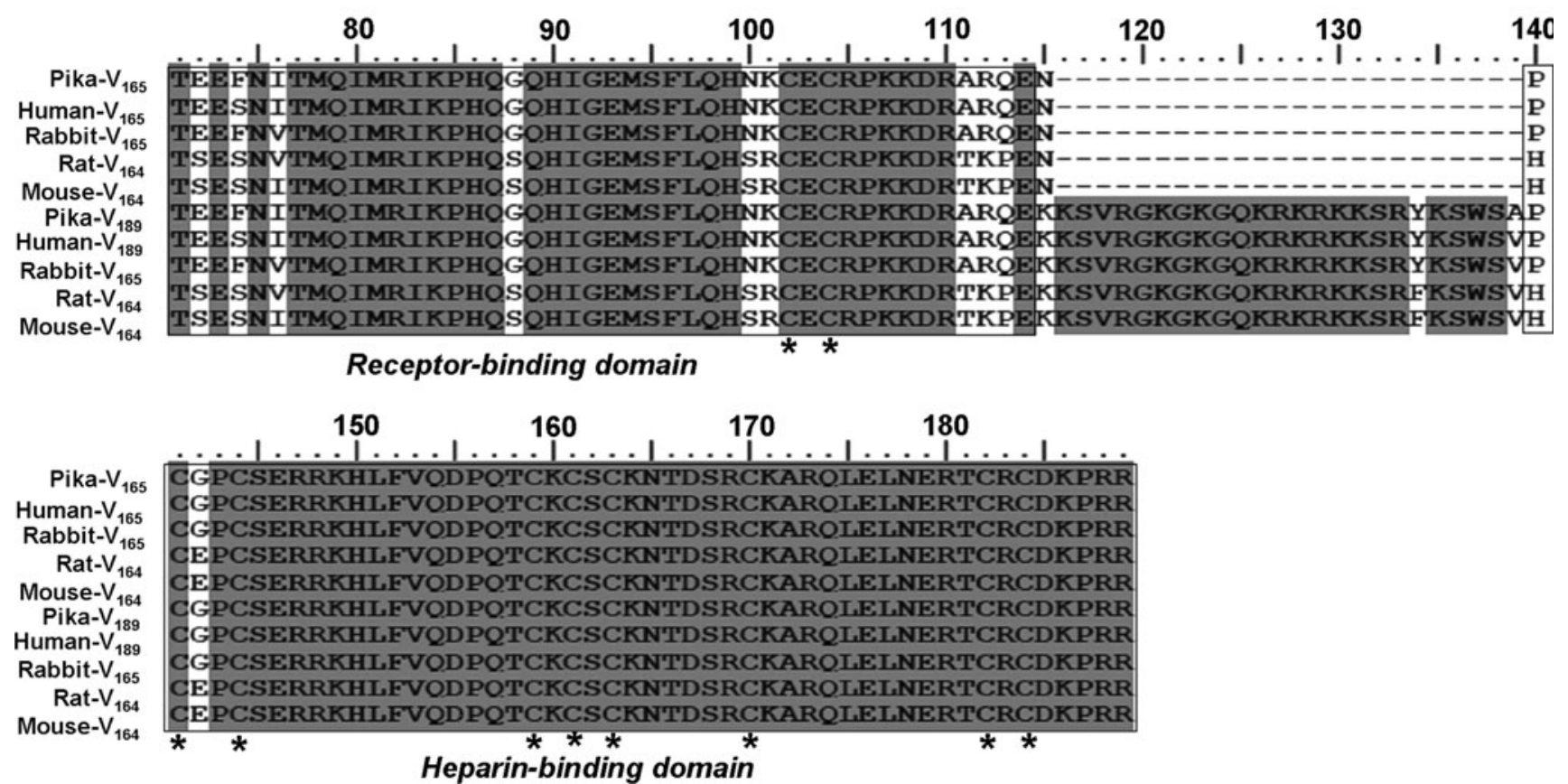

FIG. 4. Multiple alignment of the amino acid sequence of plateau pika VEGF $165 / 189$ with those from human (Homo sapiens), rabbit (Oryctolagus cuniculus), Norway rat (Rattus norvegicus), and mouse (Mus musculus). Identical amino acids are shaded with a gray background. The receptor-binding domain and heparin-binding domain are boxed. Conserved cystein residues are indicated by the asterisks.

\section{Expression of total VEGF in plateau pika}

Total VEGF mRNA was expressed in a tissue-specific mode in the plateau pika. The mRNA levels of VEGF were the highest in lungs, and the levels were higher in hearts, livers, kidneys, and muscles than in spleens and brains. This expression pattern in the pika is similar with that in mouse living at sea level (data not shown).

\section{Expression patterns of plateau pika VEGF 165 and VEGF 189}

To study the expression patterns of pika $\mathrm{VEGF}_{165}$ and VEGF $_{189}$, RT-PCR was performed using $m$ RNA from different tissues. Results demonstrate that $\mathrm{VEGF}_{165}$ and $\mathrm{VEGF}_{189}$ were widely expressed in the pika (heart, lung, liver, spleen, kidney, brain, and muscle), but the relative amounts of $\mathrm{VEGF}_{165}$ and VEGF $_{189} \mathrm{mRNAs}$ varied among tissues (Fig. 7A). To determine the relative levels of $\mathrm{VEGF}_{165}$ and $\mathrm{VEGF}_{189}$ mRNA accurately, a real-time RT-PCR analysis was performed. The results of this analysis showed that the expression of the two isoforms was quite distinct in the different tissues of the pika. $\mathrm{VEGF}_{189}$ was most highly expressed in the lung, but also highly abundant in the heart. The expression of VEGF $_{165}$ was not as high as $\mathrm{VEGF}_{189}$ in the lung and heart and showed similar levels in the heart, lung, liver, and kidney. The relative expression levels of $\mathrm{VEGF}_{165}$ and $\mathrm{VEGF}_{189}$ mRNA showed some interesting patterns: $\mathrm{VEGF}_{189}$ was the dominant isoform in the heart, lung, and muscle tissues, while both were roughly equally abundant in liver and kidney tissues and both were expressed weakly in the spleen and brain tissues (Fig. 7B). Despite low expression, the level of $\mathrm{VEGF}_{189}$ is higher than that of $\mathrm{VEGF}_{165}$ in the brain.

\section{Expression of VEGFs in plateau pika in relation to habitat altitude}

Since VEGF plays an important role in the tissue response to hypoxia, we questioned whether the expression of $\mathrm{VEGF}_{165}$ and VEGF $_{189}$ would be different in the pikas inhabiting different altitudes. To resolve this question, we determined the mRNA levels of $\mathrm{VEGF}_{165}$ and $\mathrm{VEGF}_{189}$ in the brain, muscle, and lung tissues of pikas inhabiting altitudes of 3200 and $4750 \mathrm{~m}$. Then $\mathrm{VEGF}_{165}$ and $\mathrm{VEGF}_{189}$ mRNA levels were normalized by $\beta$-actin since $\beta$-actin, as a housekeeping gene, has no significant difference between these two groups (Li et al., 

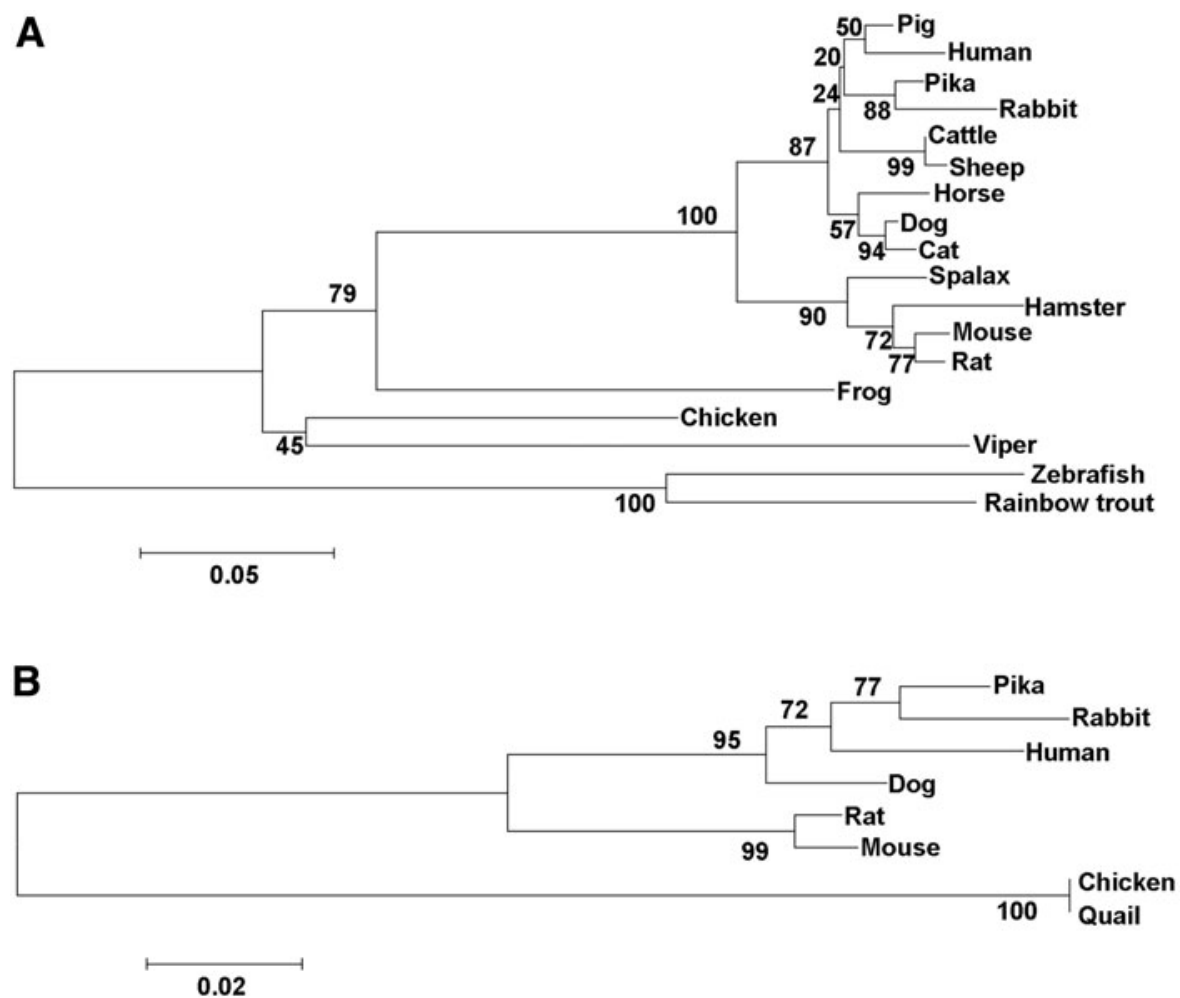

FIG. 5. Phylogenetic relationships of the plateau pika and other species VEGF $165 / 164$ (A) and VEGF $189 / 188$

(B).

2009).The data show that $\mathrm{VEGF}_{165}$ and $\mathrm{VEGF}_{189}$ mRNA levels were significantly increased in the brains of the animals inhabiting the altitude of $4700 \mathrm{~m}$, compared with those at $3200 \mathrm{~m}(p<0.01$ and $p<0.01$, respectively). The levels of $\mathrm{VEGF}_{189}$ appear to be increased more than those of $\mathrm{VEGF}_{165}$ (Fig. 8A). In the muscle (Fig. 8B) and lung (Fig. 8C), VEGF 189 levels were also significantly increased in the animals inhabiting an altitude of $4750 \mathrm{~m}$ compared to those at $3200 \mathrm{~m}$ $\left(p<0.01\right.$ and $p<0.001$, respectively), while $\mathrm{VEGF}_{165}$ shows no significant difference. These data indicated that $\mathrm{VEGF}_{189}$ mRNA levels are increased in the animals that inhabit higher altitudes.
Pika-V 165 Human- $V_{165}$

Pika-V 189 Human- $V_{189}$

Pika-V 165 Human-V 165

Pika-V Human- $\mathrm{V}_{189}$

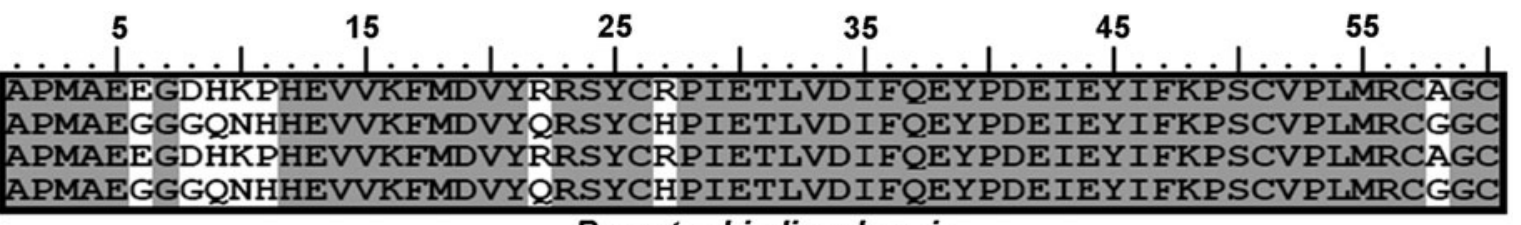

65

75
95

105

115

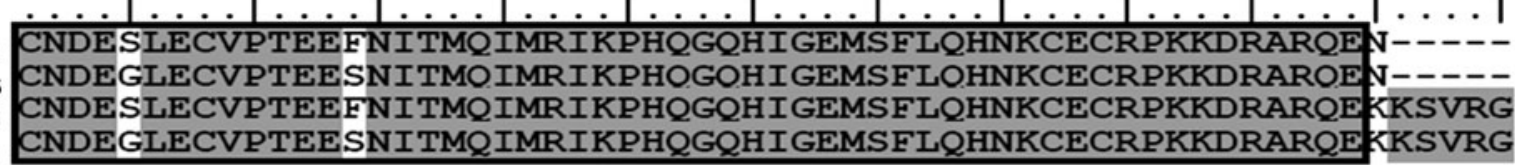

$$
125135 \text { Receptor-binding domain }
$$

125

155

165

175

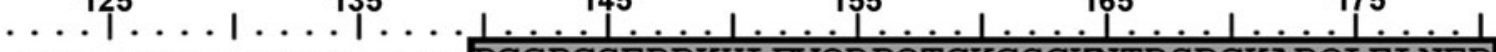

Pika-V 165

Human- $V_{165}$

Pika-V

Human- $V_{189}^{189}$

KGKGQKRKRKKSRYKSWSA PCGPCSERRKHLFVQDPQTCKCSCKNTDSRCKARQLELNER
KGKGQKRKRKKSRYKSWSVPCGPCSERRKHLFVQDPQTCKCSCKNTDSRCKARQLELNER

185

Pika-V 165

Human-V $V_{165}$

PCRCDKPRR

Human- $V_{189}^{189}$ TCRCDKPRR

FIG. 6. Comparison of the amino acid sequences of $\mathrm{VEGF}_{165}$ and $\mathrm{VEGF}_{189}$ between plateau pika and human. Differences between the sequences are shown in the white region. A receptor-binding domain and a heparin-binding domain are boxed. 

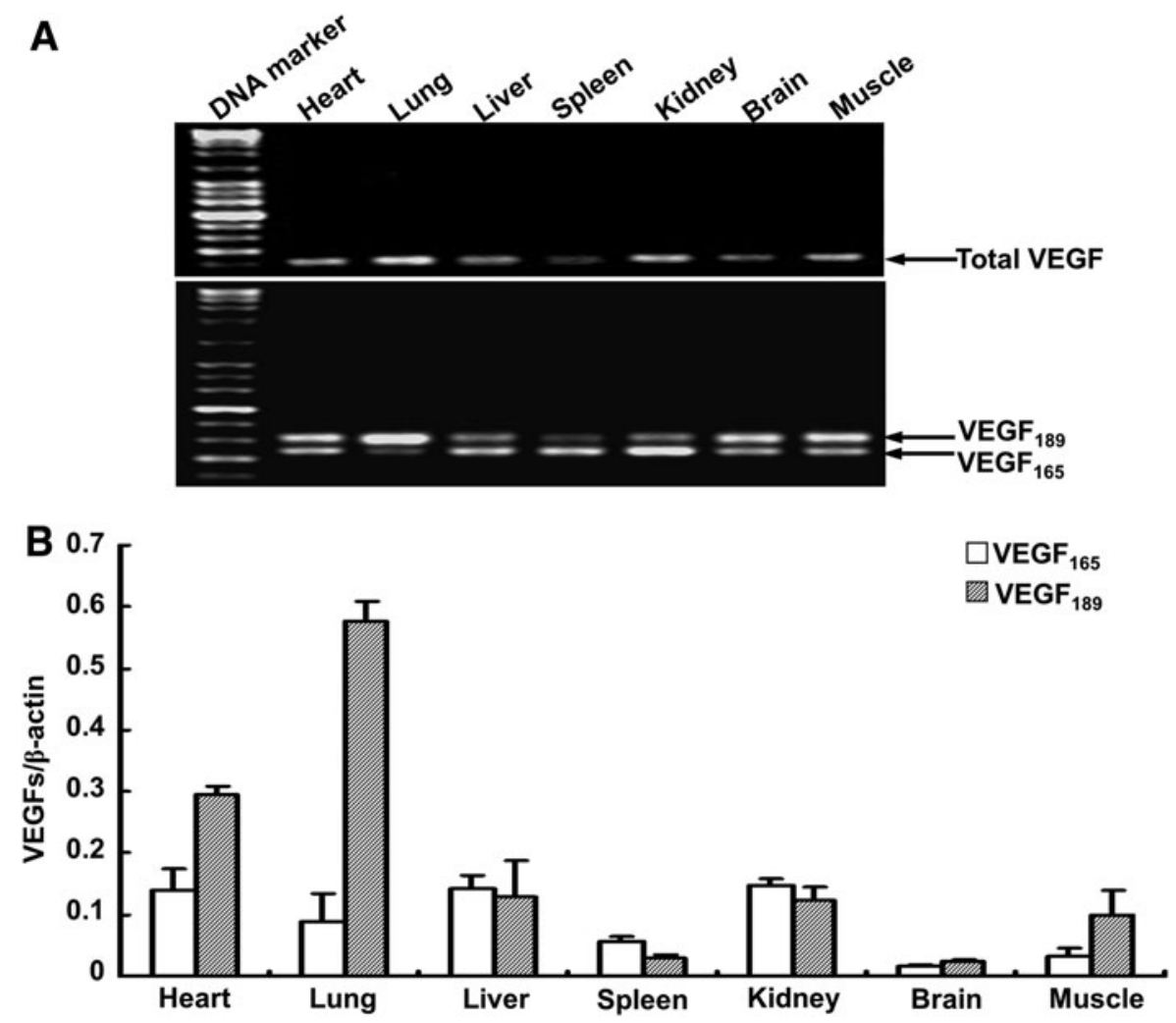

FIG. 7. Expression of total VEGF,VEGF 165 and $\mathrm{VEGF}_{189}$ mRNA in different plateau pika tissues. (A) RT-PCR analysis of total VEGF, VEGF 165 , and VEGF $_{189}$ expression in the pika heart, lung, liver, spleen, kidney, brain, and muscle. (B) Transcript levels of $\mathrm{VEGF}_{165}$ and $\mathrm{VEGF}_{189}$ assessed by real time RT-PCR. Expression levels were normalized to $\beta$-actin. All results are expressed as means \pm S.D. $(n=10)$.

\section{Discussion}

To adapt to a high-altitude environment, plateau animals have developed unique characteristics. The plateau pika, as a typical plateau mammal, has been extensively studied to understand this adaptation. HIF- $1 \alpha$ (Li et al., 2008, Zhao et al., 2004) and leptin (Yang et al., 2006) expression, and leptin (Yang et al., 2008) and $\mathrm{Hb}$ (Yingzhong et al., 2007) amino acid
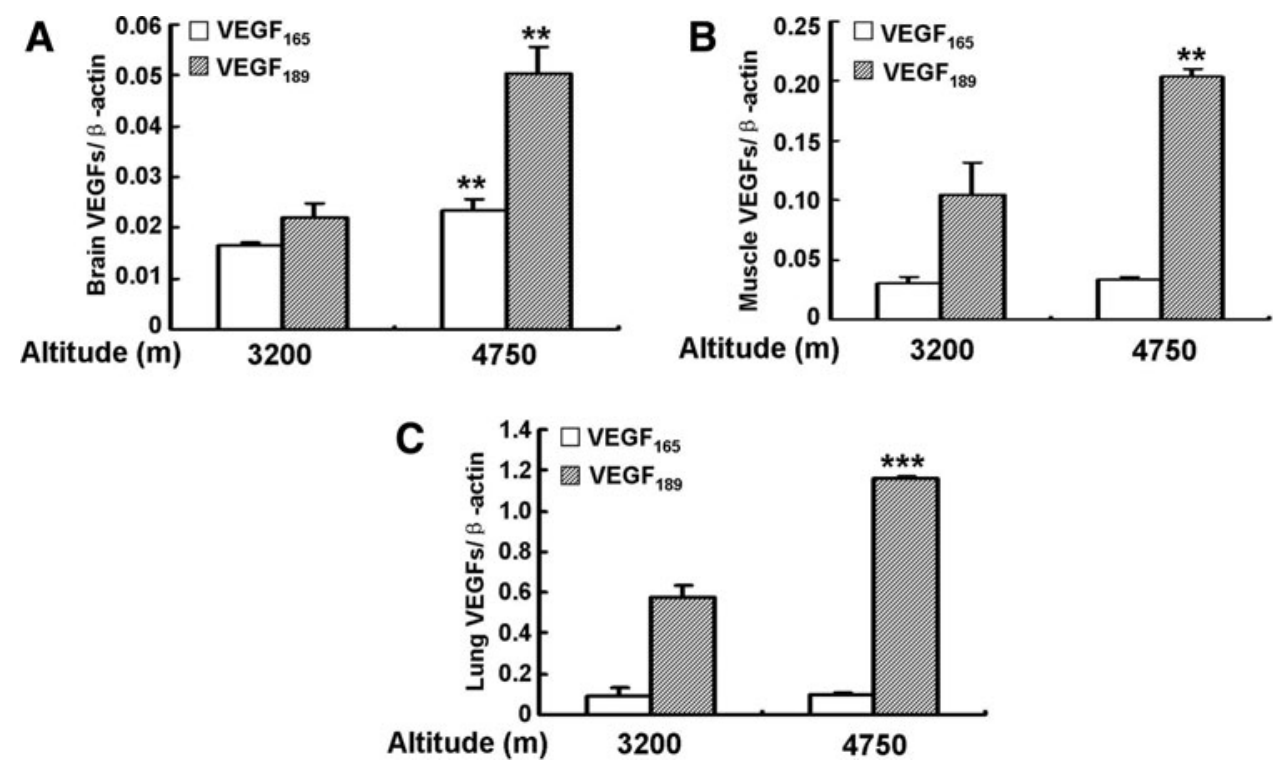

FIG. 8. Comparison of $\mathrm{VEGF}_{165}$ and $\mathrm{VEGF}_{189}$ mRNA levels in plateau pikas inhabiting different altitudes. mRNA expression levels of $\mathrm{VEGF}_{165}$ and $\mathrm{VEGF}_{189}$ in brain (A), muscle (B), and lung (C) of the pika collected at two different altitudes $(3200$ and $4750 \mathrm{~m})$ are shown. Expression levels were normalized to $\beta$-actin. All the results are expressed as means \pm S.D. $(n=10)$. Asterisks indicate significant differences compared with the altitude of $3200 \mathrm{~m}\left({ }^{* *} p<0.01,{ }^{* * *} p<0.001\right)$. 
substitutions have been linked to adaptation in the pika. Here we present for the first time the isolation and characterization of VEGF, another gene that is sensitive to the environment, from the plateau animal. The novel expression pattern of $\mathrm{VEGF}_{165}$ and $\mathrm{VEGF}_{189}$ may be involved in adaptation of the pika since phylogenetic analysis reveals the conservation of pika $\mathrm{VEGF}_{165}$ and $\mathrm{VEGF}_{189}$.

Several studies have shown that $\mathrm{VEGF}_{165 / 164}$ and VEGF 189 / 188 isoforms mRNA display tissue-specific expression. VEGF $_{188}$ is the most abundant isoform in lung and heart, whereas $\mathrm{VEGF}_{164}$ is more highly expressed in murine muscle, brain, liver, spleen, and kidney (Bacic et al., 1995, Ng et al., 2001). Watkins et al. (1999) reported that $\mathrm{VEGF}_{189}$ is most highly expressed in rabbit lung, whereas VEGF $_{165}$ is most abundant in liver, spleen, and kidney. The predominance of $\mathrm{VEGF}_{188}$ in heart and lung distinguishes these two tissues from all others examined. This suggests that $\mathrm{VEGF}_{189 / 188}$ may play a specific or exclusive role in cardiopulmonary function. It has been demonstrated that $\mathrm{VEGF}_{188}$ produced by the rat pulmonary epithelium mediates the assembly and stabilization of the highly organized vessel network that surrounds the alveoli (Ng et al., 2001).

In our study, RT-PCR and real time RT-PCR-based expression analysis revealed that $\mathrm{VEGF}_{189}$ mRNA expression was significantly higher than $\mathrm{VEGF}_{165}$ in the plateau pika brain and muscle. This is a novel finding because earlier studies had shown that $\mathrm{VEGF}_{165}$ mRNA expression is higher than $\mathrm{VEGF}_{189}$ in the brain and muscle of mice and rat, animals found at sea level (Bacic et al., 1995, Ng et al., 2001). The recent study (Zheng et al., 2011) found that the microvessel density is significantly increased in the pika brain compared with sea-level rat brain $\left(602.1 \pm 66.98\right.$ vs. $426.75 \pm 58.25$ microvessels per $\mathrm{mm}^{2}$ ). Therefore, higher-level $\mathrm{VEGF}_{189}$ may be required for more microvessels in pika brain to adapt to hypoxia since $\mathrm{VEGF}_{189}$ was reported to have the capability to induce the most-dense, small, sprouting microvessels (Yuan et al., 2011). However, there is a lower microvessel density but higher $\mathrm{Mb}$ (myoglobin) in the pika skeletal muscle compared to sea-level rat muscle (microvessel density: $603.70 \pm 115.88$ vs. $1009.63 \pm 138.48$ microvessels per $\mathrm{mm}^{2}$; Mb: $0.91 \pm 0.09$ vs. $\left.-0.08 \pm 0.49 \log \mathrm{C}_{\mathrm{Mb}} / \log \mathrm{C}_{\mathrm{GAPDH}}\right)$. Yan, et al.(2009) found the muscle-specific $\mathrm{Mb}$ overexpressing transgenic mice had a lower vascular density, although it, at VEGF level, has similar response to ischemia injury with wildtype mouse. VEGF overexpression has been reported to increase the $\mathrm{Mb}$ expression rather than angiographic score of collateral arteries in the mouse muscle (van Weel et al., 2004). Therefore, the higher-level VEGF $_{189}$ in the pika muscle may be involved in its adaptation to high altitude hypoxia through increasing $\mathrm{Mb}$ expression since $\mathrm{Mb}$ has higher affinity to $\mathrm{O}_{2}$.

Changes in the ratio of VEGF isoforms have been demonstrated to be related to responses to systemic hypoxia (Hofstaetter et al., 2004) or glucose starvation (Zhang et al., 2002). Systemic hypoxia has been shown to differentially affect expression of VEGF isoform mRNA (Marti et al., 1998, Watkins et al., 1999). Birot et al. (2004) have reported that $\mathrm{VEGF}_{188}$ levels are transiently elevated in the rat heart in response to systemic hypoxia, whereas no change was found in $\mathrm{VEGF}_{164}$ mRNA levels. Transient elevation of VEGF has been demonstrated to occur at the time of initial adaptation in the mouse brain in response to chronic hypoxia (Kuo et al., 1999). Hypoxia is well known to be a major feature of the plateau environment. In this study, we found that VEGF $_{189}$ mRNA levels remain higher in the brain and muscle of native pika inhabiting higher altitudes.
This may account for the higher abundance of $\mathrm{VEGF}_{189}$ compared with $\mathrm{VEGF}_{165}$ in the pika brain and muscle. It should be noted that the increase is permanent, not transient. This suggests that pika may need to retain relatively higher levels of VEGF $_{189}$ than VEGF $_{165}$ expression in the brain and muscle in order to adapt to the higher-altitude environments, as changes in $\mathrm{VEGF}_{165}$ expression were less than those for $\mathrm{VEGF}_{189}$ levels between pikas inhabiting different altitudes.

The two sites in the present study have an extremely cold and hypoxic plateau climate. The most obvious differences between these two sites are altitude and ambient temperature. The altitudes of the two sites are $3200 \mathrm{~m}$ and $4750 \mathrm{~m}$, with average temperatures of $-1.7^{\circ} \mathrm{C}$ and $-11.7^{\circ} \mathrm{C}$, respectively. As altitude increases and temperature decreases, the partial pressure of oxygen decreases. Thus the partial pressure of $\mathrm{O}_{2}\left(\mathrm{PO}_{2}\right)$ at higher altitude is lower than the $\mathrm{PO}_{2}$ at lower altitude. In our study, we demonstrate that under in vivo conditions, in ambient atmosphere, VEGF $_{189}$ mRNA is expressed at higher levels in lungs in pika inhabiting a higher altitude compared with those at a lower altitude. This trend is similar to the changes in HIF- $1 \alpha$ (the hypoxia inducible subunit of HIF-1) protein expression in pika lung with altitudes (Li et al., 2008). It is well known that hypoxia-induced expression of VEGF is under the control of HIF-1 in other species (Damert et al., 1997), therefore it can be deduced that the higher constitutive level of VEGF $_{189}$ mRNA in the lung may be supported by the higher constitutive levels of HIF-1 $\alpha$ protein in the pika inhabiting higher altitudes. However, Rissanen et al. (2006) found that temperature is also involved in regulation of HIF- $1 \alpha$ in crucian carp. Here, low temperature may also play an important role in altitude-related VEGF regulation (Rissanen et al., 2006), since cold is reported to be involved in angiogenesis through upregulating VEGF expression by HIF in mouse adipose tissue (Xue et al., 2009). Therefore, the two prime ecological factors, hypoxia and cold, both may play an important role in the adaption of pika to harsh altitude climates through VEGF.

In summary, we have cloned $\mathrm{VEGF}_{165}$ and $\mathrm{VEGF}_{189}$ isoforms from the plateau pika, and found that they were expressed in a tissue-specific manner. Specifically, $\mathrm{VEGE}_{189}$ has a higher expression than $\mathrm{VEGF}_{165}$ in pika brain and muscle, which may be involved in pika brain's and muscle's adaptation to hypoxia through different mechanisms. Further, VEGE 189 levels in pika brain, muscle, and lung are correlated to the altitudes of their habitat. All these changes could allow the animal to adapt to the hypoxia challenges of its natural habitat.

\section{Acknowledgments}

We thank Dr. David M. Irwin (University of Toronto) for reading and revising our manuscript, and Dr. Tong Sun and Dr. Yan-Jie Li for their help in the real-time PCR experiment

\section{Author Disclosure Statement}

The authors declare no conflicting financial interests.

This work was greatly supported by a grant from The Knowledge Innovation project of the Chinese Academy of Sciences (0254051211).

\section{References}

Anand I, Heath D, Williams D, Deen M, Ferrari R, Bergel D, and Harris P. (1988). The pulmonary circulation of some domestic animals at high altitude. Intl J Biometeorol 32:56-64. 
Anand IS, Harris E, Ferrari R, Pearce P, and Harris P. (1986). Pulmonary haemodynamics of the yak, cattle, and cross breeds at high altitude. Thorax 41:696-700.

Azwai SM, Abdouslam OE, Al-Bassam LS, Dawek AMA, and Al-Izzi SAL. (2007). Morphological characteristics of blood cells in clinically normal adult llamas (lama glama). Veterinarski Arhiv 77:69-79.

Bacic M, Edwards NA, and Merrill MJ. (1995). Differential expression of vascular endothelial growth factor (vascular permeability factor) forms in rat tissues. Growth Factors 12: 11-15.

Benavides CE, Perez R, Espinoza M, Cabello G, Riquelme R, Parer JT, and Llanos AJ. (1989). Cardiorespiratory functions in the fetal llama. Respir Physiol 75:327-334.

Birot OJ, Peinnequin A, Simler N, van Cuyck-Gandre H, Hamel R, and Bigard XA. (2004). Vascular endothelial growth factor expression in heart of rats exposed to hypobaric hypoxia: Differential response between mrna and protein. J Cell Physiol 200:107-115.

Broxmeyer HE, Cooper S, Li ZH, Lu L, Song HY, Kwon BS, Warren RE, and Donner DB. (1995). Myeloid progenitor cell regulatory effects of vascular endothelial cell growth factor. Int J Hematol 62:203-215.

Damert A, Ikeda E, and Risau W. (1997). Activator-protein-1 binding potentiates the hypoxia-induciblefactor-1-mediated hypoxia-induced transcriptional activation of vascular-endothelial growth factor expression in c6 glioma cells. Biochem J 327:419-423.

Du JZ, and Li QF. (1982). Effect of simulated hypoxia acclimation on organism, organ and hematology in ochotona curzoniae and rats. Acta Theriolog Sinica 2:35-42.

Du JZ, Li QF, and Chen XG. (1983). The changing of corticosterone level in native ochotona curzoniae. Acta Theriolog Sinica 3: 47-52.

Durmowicz AG, Hofmeister S, Kadyraliev TK, Aldashev AA, and Stenmark KR. (1993). Functional and structural adaptation of the yak pulmonary circulation to residence at high altitude. J Appl Physiol 74:2276-2285.

Forsythe JA, Jiang BH, Iyer NV, Agani F, Leung SW, Koos RD, and Semenza GL. (1996). Activation of vascular endothelial growth factor gene transcription by hypoxia-inducible factor 1. Mol Cell Biol 16:4604-4613.

Ge RL, Kubo K, Kobayashi T, Sekiguchi M, and Honda T. (1998). Blunted hypoxic pulmonary vasoconstrictive response in the rodent Ochotona curzoniae (pika) at high altitude. Am J Physiol 274:H1792-1799.

Gerber HP, Malik AK, Solar GP, et al. (2002). VEGF regulates haematopoietic stem cell survival by an internal autocrine loop mechanism. Nature 417:954-958.

Gitay-Goren H, Soker S, Vlodavsky I, and Neufeld G. (1992). The binding of vascular endothelial growth factor to its receptors is dependent on cell surface-associated heparin-like molecules. J Biol Chem 267:6093-6098.

Hattori K, Dias S, Heissig B, et al. (2001). Vascular endothelial growth factor and angiopoietin-1 stimulate postnatal hematopoiesis by recruitment of vasculogenic and hematopoietic stem cells. J Exp Med 193:1005-1014.

He JQ, Xu CH, Meng XF, Li HL, and Wang YR. (1994). Comparative analysis in transport and intake of oxygen between pikas (Ochotona curzoniae) and rats. J Prevent Med Chinese People's Liberation 12:431-435.

Hofstaetter JG, Saad FA, Samuel RE, Wunderlich L, Choi YH, and Glimcher MJ. (2004). Differential expression of VEGF isoforms and receptors in knee joint menisci under systemic hypoxia. Biochem Biophys Res Commun 324:667-672.
Jiang JC, Gama RZ, and He ML. (1991). A comparison on several hematologic values of yaks on tibet plateau at different altitudes. Acta Veterin Zootech Sinica 22:20-26.

Jiang JC, He ML, Gama RZ, and Bianba CR. (1992). Comparison on several hematologic value of goat in tibet plateau at different altitude. Southwest China J Agricult Sci 5:79-83.

Ku DD, Zaleski JK, Liu S, and Brock TA. (1993). Vascular endothelial growth factor induces EDRF-dependent relaxation in coronary arteries. Am J Physiol 265:H586-592.

Kuo NT, Benhayon D, Przybylski RJ, Martin RJ, and LaManna JC. (1999). Prolonged hypoxia increases vascular endothelial growth factor mrna and protein in adult mouse brain. J Appl Physiol 86:260-264.

Levy NS, Chung S, Furneaux H, and Levy AP. (1998). Hypoxic stabilization of vascular endothelial growth factor mrna by the rna-binding protein hur. J Biol Chem 273:6417-6423.

Li H, Ren Y, Guo S, et al. (2008). The protein level of hypoxiainducible factor-1alpha is increased in the plateau pika (Ochotona curzoniae) inhabiting high altitudes. J Exp Zool 311A:1-8.

Li HG, Ren YM, Guo SC, et al. (2009). The protein level of hypoxia-inducible factor-1alpha is increased in the plateau pika (Ochotona curzoniae) inhabiting high altitudes. J Exp Zool A, Ecolog Genetics Physiol 311:134-141.

Li Q, Sun R, Huang C, et al. (2001). Cold adaptive thermogenesis in small mammals from different geographical zones of china. Comp Biochem Physiol A Mol Integr Physiol 129:949-961.

Li QF, You ZB, Chen XG, and Du JZ. (1986). Effect of chronic hypoxia on the liver of Ochotona curzoniae and rat. Acta Theriolog Sinica 6:261-266.

Marti HH, and Risau W. (1998). Systemic hypoxia changes the organ-specific distribution of vascular endothelial growth factor and its receptors. Proc Natl Acad Sci USA 95:15809-15814.

Ng YS, Rohan R, Sunday ME, Demello DE, and D'Amore PA. (2001). Differential expression of VEGF isoforms in mouse during development and in the adult. Dev Dyn 220:112-121.

Qi XZ, Wang XJ, Zhu SH, Rao XF, Wei L, and Wei DB. (2008). Hypoxic adaptation of the hearts of plateau zokor (Myospalax baileyi) and plateau pika (Ochotona curzoniae). Acta Physiolog Sinica 60:348-354.

Rissanen E, Tranberg HK, Sollid J, Nilsson GE, and Nikinmaa M. (2006). Temperature regulates hypoxia-inducible factor-1 (hif1) in a poikilothermic vertebrate, crucian carp (Carassius carassius). J Exp Biol 209:994-1003.

Stein I, Itin A, Einat P, Skaliter R, Grossman Z, and Keshet E. (1998). Translation of vascular endothelial growth factor mrna by internal ribosome entry: Implications for translation under hypoxia. Mol Cell Biol 18:3112-3119.

Tamura K, Dudley J, Nei M, and Kumar S. (2007). Mega4: Molecular evolutionary genetics analysis (mega) software version 4.0. Mol Biol Evol 24:1596-1599.

van Weel V, Deckers MM, Grimbergen JM, et al. (2004). Vascular endothelial growth factor overexpression in ischemic skeletal muscle enhances myoglobin expression in vivo. Circ Res 95:58-66.

Wang XJ, Wei DB, Wei L, Qi XZ, and Zhu SH. (2008). Characteristics of pulmonary acinus structure in the plateau zokor (Myospalax baileyi) and plateau pika (Ochotona curzoniae). Acta Zoolog Sinica 54:531-539.

Watkins RH, D'Angio CT, Ryan RM, Patel A, and Maniscalco WM. (1999). Differential expression of VEGF mRNA splice variants in newborn and adult hyperoxic lung injury. Am J Physiol 276:L858-867.

Wei DB, Wei L, Zhang JM, and Yu HY. (2006). Blood-gas properties of plateau zokor (Myospalax baileyi). Comp Biochem Physiol A Mol Integr Physiol 145:372-375. 
Wu Y, and Du JZ. (2001). Study of activity of HPA in rat and Ochotona curzoniae under hypoxia. Acta Theriolog Sinica 21:195-198.

Xue Y, Petrovic N, Cao R, et al. (2009). Hypoxia-independent angiogenesis in adipose tissues during cold acclimation. Cell Metabol 9:99-109.

Yamazaki Y, and Morita T. (2006). Molecular and functional diversity of vascular endothelial growth factors. Mol. Divers 10:515-527.

Yang J, Zhao XQ, Guo SC, Li HG. Qi DL, Wang DP, and Cao JH. (2006). Leptin cDNA cloning and its mRNA expression in plateau pikas (Ochotona curzoniae) from different altitudes on Qinghai-Tibet plateau. Biochem Biophys Res Commun 345: 1405-1413.

Yang J, Wang ZL, Zhao XQ, et al. (2008). Natural selection and adaptive evolution of leptin in the ochotona family driven by the cold environmental stress. PloS One 3:e1472.

Yang YG, Guan H, Liu CW, and Li YJ. (2009). Myoglobin overexpression attenuates angiogenic response in hindlimb ischemia in mice. Chin Med J 122:1056-1060.

Ye RR, Cao YF, and Bai QH. (1994). Blood indices of plateau pika and relationship with hypoxia adaptation. Animals Sci Sinica 2:115-120.

Yingzhong Y, Yue C, Guoen J, et al. (2007). Molecular cloning and characterization of hemoglobin alpha and beta chains from plateau pika (Ochotona curzoniae) living at high altitude. Gene 403:118-124.

Yuan A, Lin CY, Chou CH, et al. (2011). Functional and structural characteristics of tumor angiogenesis in lung cancers overexpressing different VEGF isoforms assessed by DCEand SSCE-MRI. PloS One 6:e16062.

Zhang L, Conejo-Garcia JR, Yang N, et al. (2002). Different effects of glucose starvation on expression and stability of VEGF mRNA isoforms in murine ovarian cancer cells. Biochem Biophys Res Commun 292 860-868.
Zhao TB, Ning HX, Zhu SS, et al. (2004). Cloning of hypoxiainducible factor 1alpha cdna from a high hypoxia tolerant mammal-plateau pika (Ochotona curzoniae). Biochem Biophys Res Commun 316:565-572.

Zheng YN, Zhu RJ, Wang DW, Wei L, and Wei DB. (2011). [gene coding and mRNA expression of vascular endothelial growth factor as well as microvessel density in brain of plateau zokor: Comparison with other rodents]. Sheng li xue bao: [Acta Physiolog Sinica] 63:155-163.

Zhou L, Yang SM, Yu ZY, et al. (2007). Genetic diversity and differentiation in four natural populations of plateau pika (Ochotona curzoniae). Acta Theriolog Sinica 27:8.

Address correspondence to: Xinquan Zhao

Northwest Institute of Plateau Biology

The Chinese Academy of Sciences

Xining 810001

People's Republic of China

E-mail: xqzhao@nwipb.cas.cn

and

Zhijie Chang

Department of Biological Sciences and Biotechnology

State Key Laboratory of Biomembrane and Membrane Biotechnology

Tsinghua University School of Medicine Beijing 100084

People's Republic of China

E-mail: zhijiec@tsinghua.edu.cn

Received January 29, 2013; accepted in final form June 7, 2013. 